\title{
EFFECT OF DYNAMIC LOADS ON THE COMPRESSIBILITY BEHAVIOR OF PEAT SOIL REINFORCED BY BAMBOO GRIDS
}

\author{
Aazokhi Waruwu*, Rika Deni Susanti, Johan Adolf Putra Buulolo \\ Institut Teknologi Medan, Department of Civil Engineering, Indonesia
}

The compression behavior of peat was investigated by a program of static and dynamic load testing. The comprehensive model tests were conducted in the laboratory to evaluate the effect of loading sequences on the behavior of peat soil. The result test indicated that compression behavior of peat soil was significantly influenced by loading sequences and reinforcement of bamboo grids. The compression behavior after the dynamic load appears smaller than before the dynamic load. Reinforcement of bamboo grids can reduce the compressibility of peat soil, especially for one layer and two layers of bamboo grid, while for three layers of bamboo grid resulted in similar settlement for two layers of bamboo grid on the pressure above $9 \mathrm{kPa}$.

Key words: Soils, Peat, Loads, Grid, Dynamics, Compression

\section{INTRODUCTION}

Peat is usually noted for its very low unit weight and shear strength, very high compressibility, and high settlement. The viscous nature of peat behavior gives rise to phenomena such as secondary compression, creep, and stress relaxation. This aspect of peat behavior leads to its frequent characterization as a viscous fluid for problems in which long-term deformation is important [01]. The elasticity modulus and permeability coefficient influence the value of settlement [02].

Kallioglou et al. [03] stated that organic soils as peat are inherently variable materials and the results of the laboratory test involving a limited number of tests and type of soils are not sufficient to define the behavior of these organic soils. The findings of this study may contribute to the understanding of the dynamic properties of organic soils, and its results could be applicable to organic soils at the infrastructures, that were formed under similar geologic and depositional conditions. The geological structure is one of the relevant assessment components in Indonesia as a tropical country [17].

Soil parameters and water absorption dapat digunakan untuk analysis of landslide occurrence

Peat is one of the most problematic sub-soil foundations. It has high compressibility, low shear strength, and excessive and long-term settlement when subjected to imposed loads of construction [04]. The fibrous peats with low ash content have very high compressive behavior and dominated by secondary compression [5]. Many structures have been built that cross over peatland areas consisting of fully saturated soils with high organic fibrous content. Foundation design and construction in these highly compressible soils hereafter referred to as peat, are extremely important, especially in those locations where creep of the soil mass has been investigated and where seismic activity is high [06]. The response of geomaterials to dynamic loading has been of interest to geotechnical engineers and other engineerers for many years. Peat is a complex material whose dynamic properties may depend on factors that were not observed in the testing program [01].

The dynamic response of peaty organic soils is not well understood but its poor competency as an engineer is well known. Its use as a subgrade is generally avoided through careful selection of project location, or removal and replacement with the better material. In certain situations, organic soils as peat are inevitable because of prior land use and subsequent development of infrastructure [07].

Reinforcement of soil as peat and soft clay has been studied, among others, the combination of geotextile bamboo as reinforcement of soft soil [8]; the bamboo grid reinforcement for soil with using triaxial test [9]; the bamboo grids and bamboo cells as reinforcement for soft soil [10]; the bamboo grids as reinforcement of peat soil under shallow foundations [11] and [12]; peat reinforced with bamboo grid under embankment [13]; and nailed slab system supported embankment on peat soil [04] and [14]. Bamboo grid can improve the modulus of subgrade and shear modulus of peat soil [18].

Marto and Othman [08] stated that the bamboo square pattern takes the load from the backfill material and hence, decreased the settlement much better compared to the others. On the other hands, the square pattern of bamboo formed an interlock to resist horizontal shear stress and increase the stiffness of bamboo, hence distributing vertical pressure evenly. Bamboo grid reinforcement is potential in reducing settlement of peat under embankment load until $36 \%$ to $64 \%$, thus it can be used as the material for reinforcement on peat under embankment load. The considered number of bamboo grid layers is about 2 - 3 layers [13]. In addition to benefits as described earlier, the use of bamboo grids is not good when used in changing weather conditions, but the use of reinforcement on peat soils is very good because bamboo grids are embedded in the peat layer. 
The experimental study of the dynamic testing in saturated peat indicated that the behavior of this material is complex and further research is required to confidently predict its behavior in the absence of field test [06]. The effective method for improvement of peat is preloading, it consists of applying a load in the form of the embankment load [04]. The preloading is able to accelerate the compression and increase the bearing capacity of peat [15]. The embankment load with the loading-unloading method can reduce the compressibility of peat, it is capable to speed up the compressibility of peat soils [05].

Combination of preloading and bamboo reinforced can improve peat soil, but the reduction of settlement due to embankment load as a static load is smaller on the greater embankment load. The loading rate and preloading time affect the bearing capacity of the nailed-slab system and the characteristics settlement of peat soil. Stage loading with longer period produces higher bearing capacity than direct load. Likewise, the loading-unloading generate the better bearing capacity of the nailed-slab system than stage loading for load increment duration of 24 hours [14].

The height and duration of embankment affect the stability and settlement [13]. Installation of bamboo piles combined with bamboo grids is able to reduce the settlement and reduce the deflection of the bamboo grid and ultimately can maintain the stability of the embankment [16].

Comprehensive model tests are conducted in the laboratory to evaluate the effect of loading sequences on the behavior of peat soil reinforced by bamboo grids. Dynamic loading is expected to increase the reduction of settlement, so that the bearing and modulus of subgrade reaction can increase. This paper discusses the effect of loading sequences and bamboo grid as reinforcement in reducing the settlement and increasing the modulus of subgrade reaction of peat soil.

\section{RESEARCH METHODS}

The samples used in the experiments are peat soil retrieved from a site in Bagansiapiapi, Riau. Index properties of peat soils are the bulk density of $10.15 \mathrm{kN} / \mathrm{m}^{3}$, water content of $587 \%$, organic content of $95.94 \%$, fiber content of $27.92 \%$, and ash content of $4.06 \%$. These high peat soils had considerably different organic characteristics from those used in previous studies of properties [13].

The model test consisted of a $L$ of $1.2 \mathrm{~m}$, a $D$ of $0.2 \mathrm{~m}$, a B of $0.34 \mathrm{~m}$, a h of $0.5 \mathrm{~m}$, a H of $0.4 \mathrm{~m}$, a of $0.02 \mathrm{~m}$, a h1 of $0.05 \mathrm{~m}, \mathrm{ah} 2$ of $0.05 \mathrm{~m}$, and a h3 of $0.05 \mathrm{~m}$ (Figure 1). The peat sample was compacted in 5 layers with the thickness of each layer $0.1 \mathrm{~m}$. Each layer was compacted close in situ density and water content. The 4th and 5th layers were reinforced using a layer bamboo grid, two-layer bamboo grid, and three-layer bamboo grid that was wrapped in peat soil (Figure 2).

The comprehensive model tests were conducted in the laboratory to evaluate the effect of loading sequences on the behavior of peat soil. The model program consisted of static and dynamic tests of a $20 \mathrm{~cm}$ diameter of the plate, the bamboo grid in peat soil. A series of cyclic load tests, with settlement measurements, were run first static load at pressurefrom 0 to $3.16 \mathrm{kPa}$, first dynamic load at pressure 3.16 to $7.42 \mathrm{kPa}$ for 5 cycles, second static load at pressurefrom 3.16 to $9.22 \mathrm{kPa}$, second dynamic load at pressure 9.22 to $11.36 \mathrm{kPa}$ for 8 cycles, and third static load from $3.16 \mathrm{kPa}$ until failure. The initial pressure is taken as $3.17 \mathrm{kPa}$ as preloading, because at this pressure the behavior of the peat soil used is still in elastic condition. Photograph of the completed model testing is shown in Figure 3.

This study discussed about The relationship betweens vs $\sigma$ for reinforced peat under dynamic load and Result comparison of reduction of settlement for dynamic load and static load.

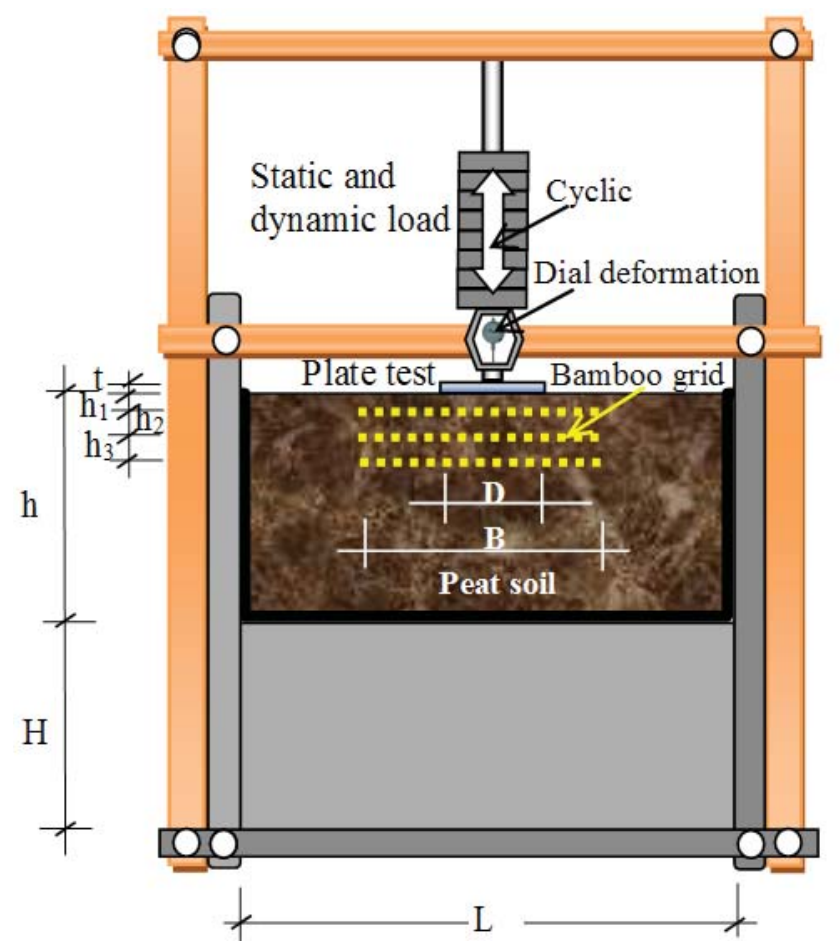

Figure 1: Model dimensions and bamboo grid configuration

\section{RESULTS AND DISCUSSION}

\section{Result of Static Load Test}

The plate load test with static loads is performed on peat soil with and without reinforcement. The compressibility behavior of the static load test for peat without reinforcement can be seen in Figure 4, while for peat with one layer of bamboo grid reinforcement seen in Figure 5. The static load is performed before dynamic load as preloading and after the first and second dynamic loads. The compressibility of peat without reinforcement is greater than the compressibility of peat with reinforcement. 


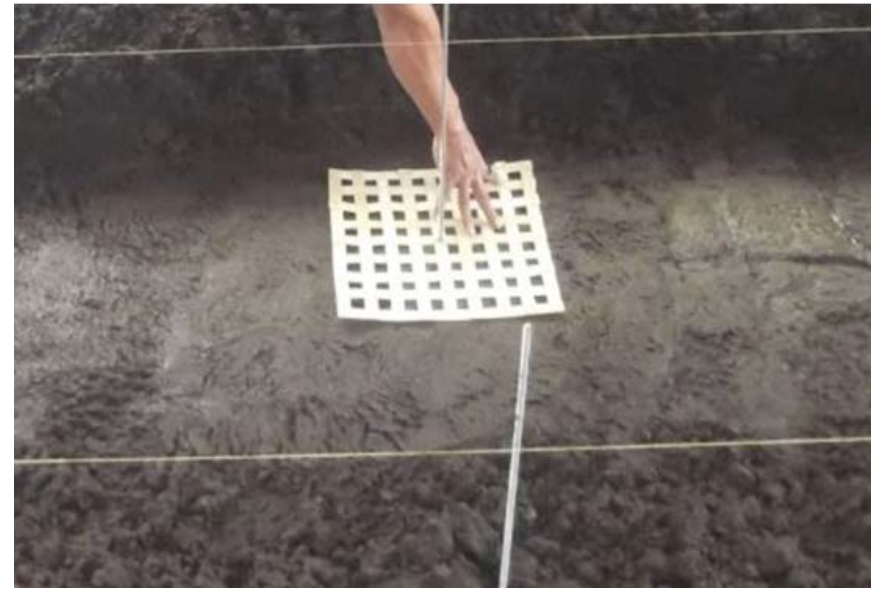

Figure 2: Bamboo grid reinforcement models

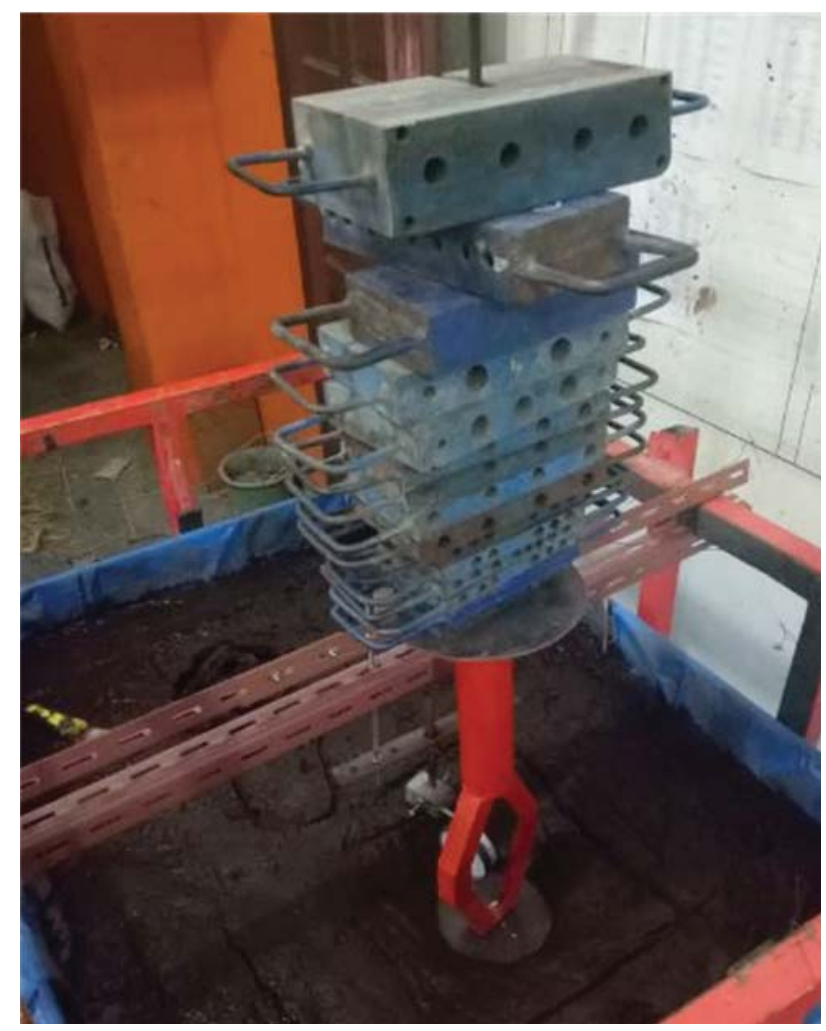

Figure 3: Photographs of the completed model

Both types of static load testing on peat with and without reinforcement seen capable to minimize peat compression. In addition to preloading and reinforcement, dynamic loads can also reduce the compression of peat soils. This is evident from the smaller peat compression behavior after the dynamic load. The smaller peat compression produces the higher bearing capacity of peat soils. This is seen in the increase in loads received by peat soils.

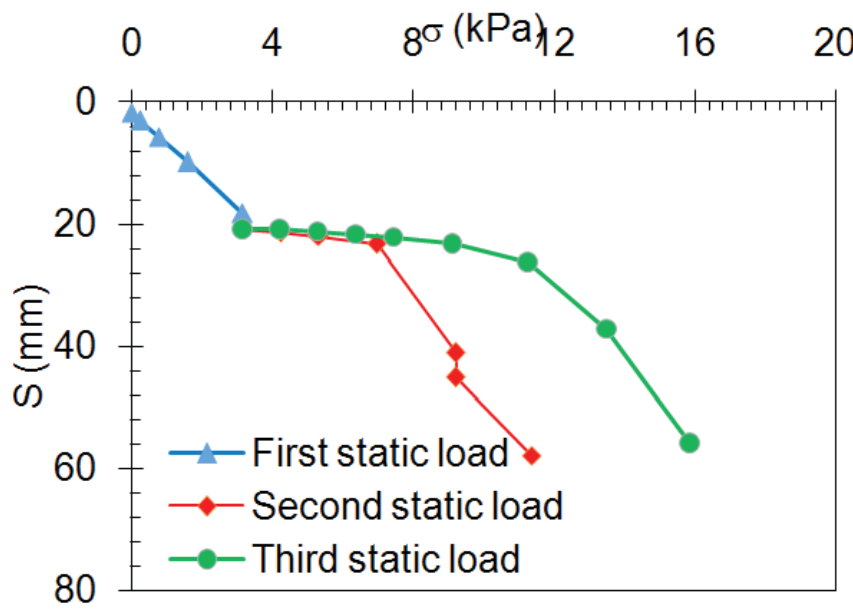

Figure 4: The relationship between $S$ vs $\sigma$ for unreinforced peat under static load

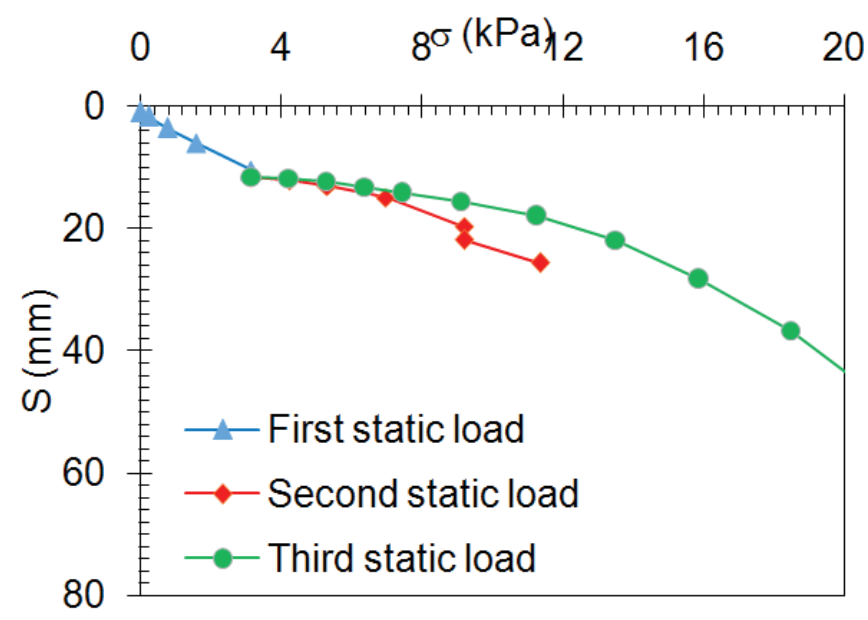

Figure 5: The relationship between $S$ vs $\sigma$ for reinforced peat under static load

\section{Result of Dynamic Load Test}

The dynamic load test is performed after the first and second static load. The dynamic load test is distinguished on peat with and without reinforcement. Figure 6 shows the results of dynamic load testing for peat without reinforcement. The results of dynamic load test on peat with one layer reinforcement are shown in Figure 7. Similarly for static load test, in the dynamic load test is seen that the reinforcement can minimize peat compression. The compression behavior after the dynamic load appears smaller than before the dynamic load. Peat compression after the second dynamic load is smaller than after the first dynamic load, thus the dynamic load affects the compression of the peat. 


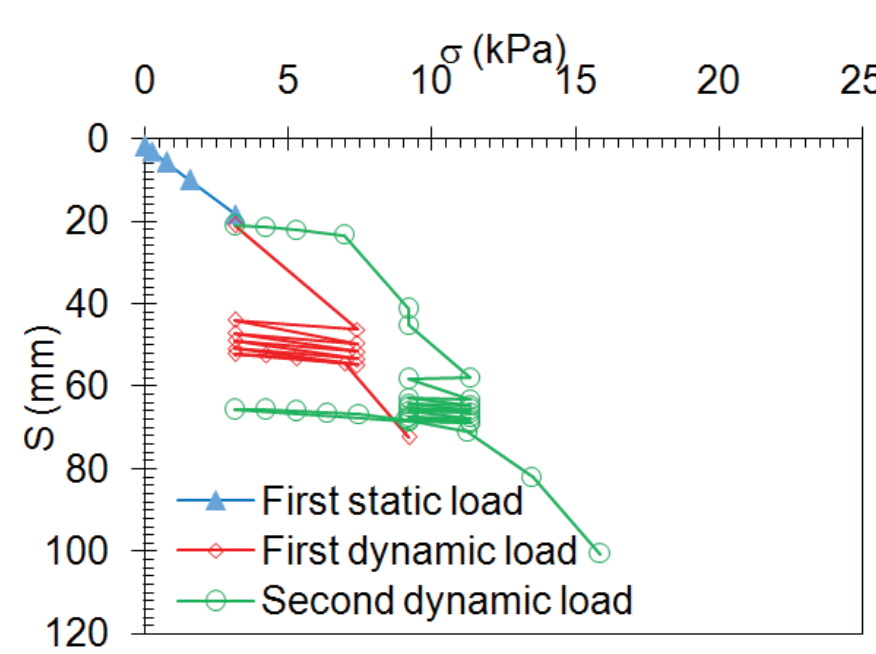

Figure 6: The relationship between $S$ vs $\sigma$ for unreinforced peat under dynamic load

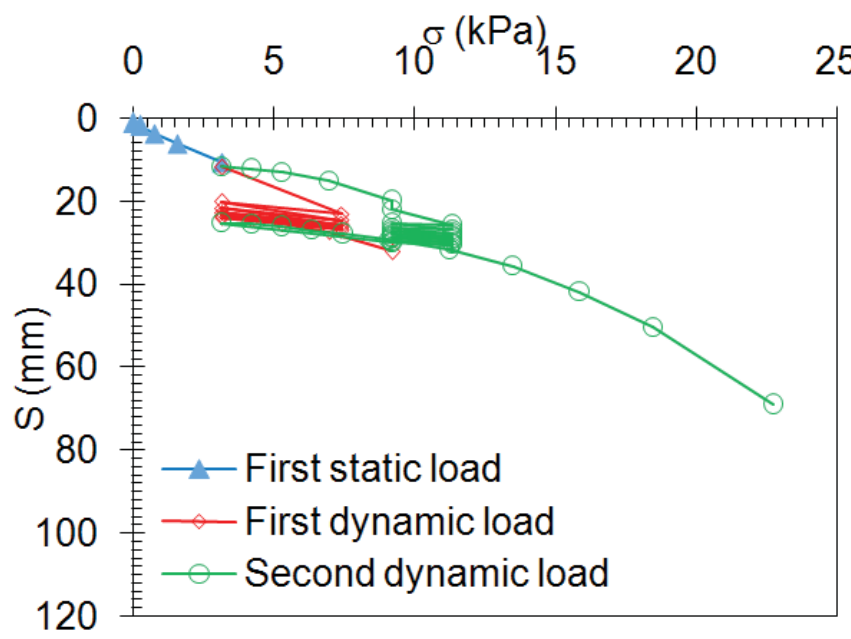

Figure 7: The relationship between $S$ vs $\sigma$ for reinforced peat under dynamic load

\section{Effect of Loading Sequences}

Effect of loading sequences on the compressibility of peat soil is presented in the reduction of settlement. In addition to reduction of settlement, the settlement ratio $(\mathrm{S})$ with the pressure $(\sigma)$ and modulus of subgrade reaction ( $k$ ) is expressed either due to loading sequences and reinforcement.

Figure 8 shows the test results of reduction of settlement on peat without reinforcement of bamboo grid. The reduction of settlement is $54 \%$ for one layer of bamboo grid, $65 \%$ for two layers of bamboo grid, $68 \%$ for three layers of bamboo grid. The reduction of settlement due to the dynamic load greater than embankment load as the static load.

Reinforcement of bamboo grids is able to reduce the compressibility of peat soil, especially for 1-layer and 2-layers of reinforcement, while for 3-layers of reinforcement resulted in the similar settlement for 2-layers of reinforcement on the pressureabove $9 \mathrm{kPa}$ (Figure 9). This can be due to the spacing between reinforcement, for this study the spacing distance used is $5 \mathrm{~cm}$ or h1/ $\mathrm{D}$ ratio $=0.25$. For one layer the distance ratio from the bottom of the plate is 0.25 , while for two layers and three layers respectively 0.5 and 0.75 . It can be interpreted that the retention distance from the bottom of the plate with a ratio greater than 0.5 is less effective in reducing the settlement on peat soil.

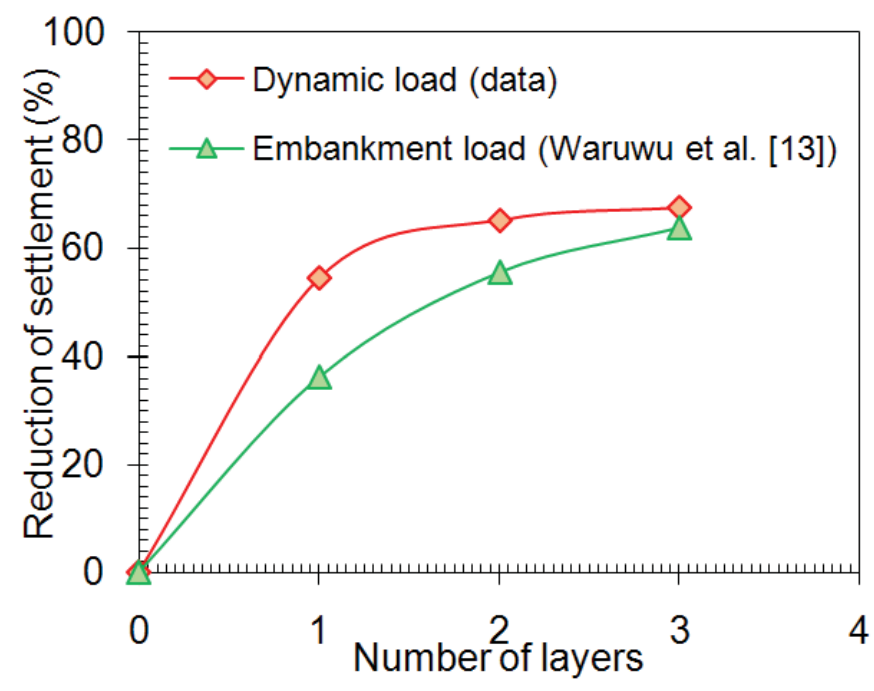

Figure 8: Result comparison of reduction of settlement for dynamic load and static load

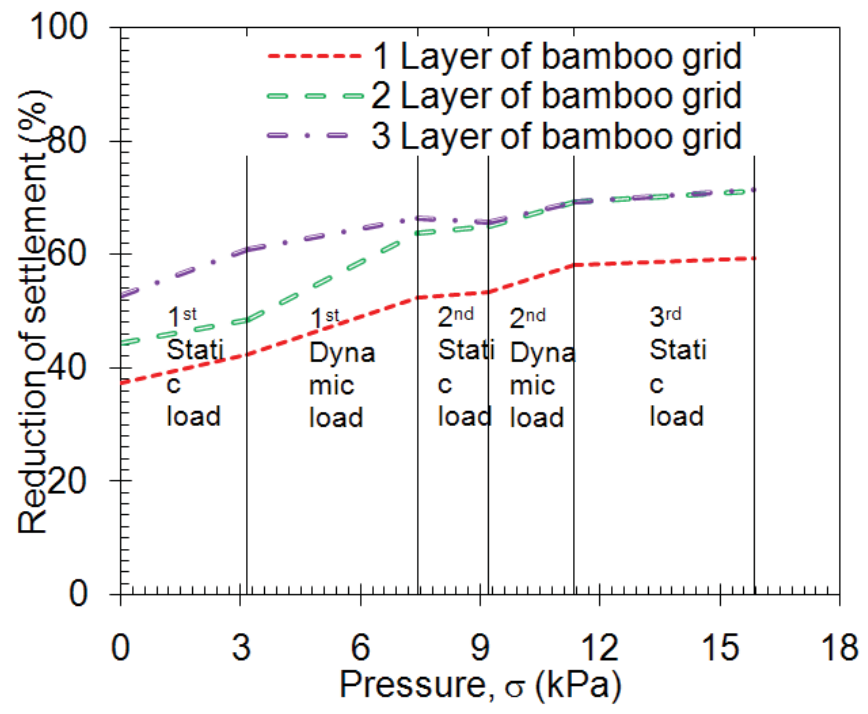

Figure 9: Effect of loading sequences on the reduction of settlement

Compressibility and bearing capacity of peat soil is affected by the loading sequences applied. The compression and bearing capacity of peat soil of the dynamically loaded soil is much better than the unload dynamic (Figure 9). Due to the dynamic load of compressibility of peat soil is smaller and the bearing capacity is greater than the unload dynamically. 
The reduction of settlement under dynamic loads is greater than the reduction of settlement under static loads.

Reduction of peat compression can be seen in the relationship of the ratio of settlement with pressure $(S / \sigma)$ and the number of dynamic load in Figure 10. In general, the number of dynamic load can reduce compression, especially for unreinforced peat and three layer of bamboo grid.

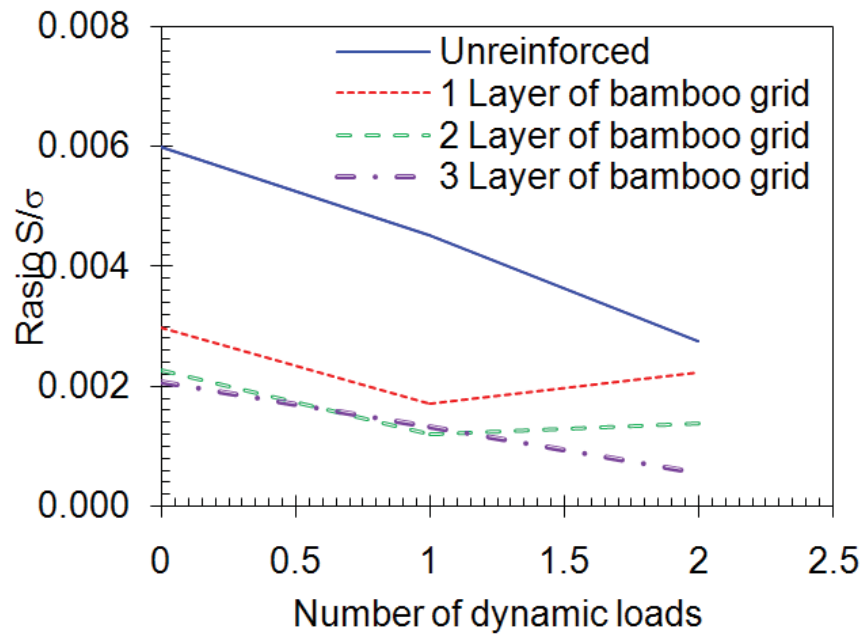

Figure 10: The relationship between ratio S/ $\sigma$ and number of dynamic loads

The reduced compression affects the modulus of subgrade reaction $(k)$. It is determined from the comparison of pressurewith the settlement and the result can be seen in Figure 11. Due to dynamic load the $k$ value increases, even though for one and two layer of bamboo grid decreases after first load dynamic, but the $k$ value for unreinforced peat and three layer of bamboo grid increases. In addition to the dynamic load, bamboo grid as reinforcement can increase $\mathrm{k}$ value.

The $k$ value improve $175 \%$ (one layer of bamboo grid), $247 \%$ (two layer of bamboo grid), $258 \%$ (three layers of bamboo grid). While the $\mathrm{k}$ values are $199 \%$ for first dynamic load and $193 \%$ for second dynamic load. In addition to reinforcement on peat soils, loading sequences can also be considered an alternative to improved compression and bearing capacity of peat soil. The loading sequences in question here is the system of applying the load on preloading for the improvement of peat soil in the field. Not only with static loads can also be done with dynamic loads.

\section{CONCLUSION}

A series of static and dynamic load test was performed on specimens of peat from Bagansiapiapi in Riau. Both types of static load testing on peat with and without reinforcement seen capable to minimize compressibility of peat soil. Similarly for static load test, in the dynamic load test is seen that the reinforcement can minimize peat compression.

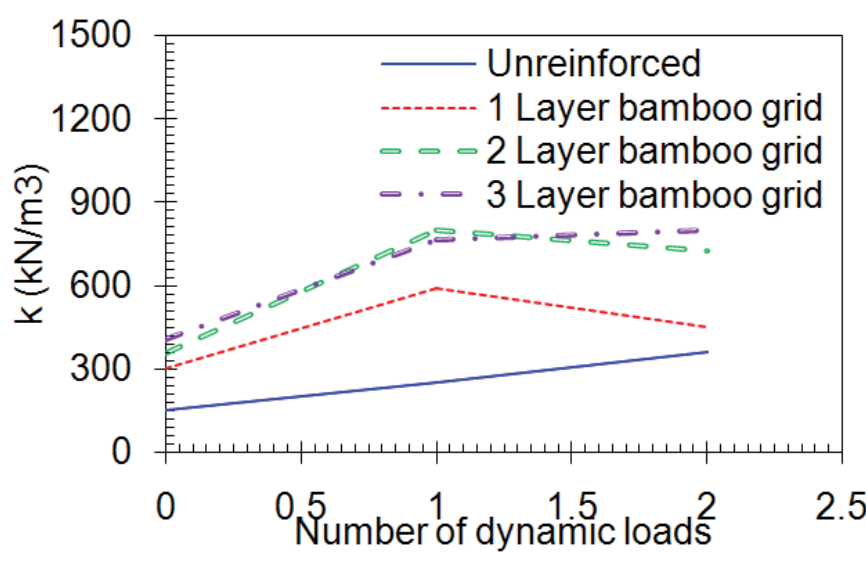

Figure 11: The relationship between modulus of subgrade reaction $(k)$ and number of dynamic load

The compression behavior after the dynamic load appears smaller than before the dynamic load. The compressibility of peat soil after the second dynamic load is smaller than after the first dynamic load, thus the dynamic load affects the compressibility of the peat.

Reinforcement of bamboo grids is able to reduce the compressibility of peat soil, especially for one layer and two layers of bamboo grid, while for three layers of bamboo grid resulted in similar settlement for two layers of bamboo grid on the pressureabove $9 \mathrm{kPa}$. The reduction of settlement are $54 \%$ for one layer of bamboo grid, $65 \%$ for two layers of bamboo grid, $68 \%$ for three layers of bamboo grid.

In general, the number of dynamic loads can reduce compression, especially for unreinforced peat and three layers of bamboo grid. The reduced compression affects the modulus of subgrade reaction $(\mathrm{k})$. The $\mathrm{k}$ value improves $175 \%$ (one layer of bamboo grid), $247 \%$ (two layers of bamboo grid), $258 \%$ (three layers of bamboo grid). While the $\mathrm{k}$ values are $199 \%$ for first dynamic load and $193 \%$ for second dynamic loads. In addition to reinforcement on peat soils, loading sequences can also be considered an alternative to improved compression and bearing capacity of peat soil.

\section{ACKNOWLEDGEMENTS}

The authors would like to thank the Directorate of Research and Community Service - Directorate General of Research and Development Strengthening - Ministry of Research, Technology, and Higher Education of the Republic of Indonesia for supporting this research.

\section{REFERENCES}

1. Kramer, S. L. (2000). Dynamic response of mercer slough peat.Journal of Geotechnical and Geoenvironmental Engineering, 126(6), 504-510. 
2. Meyer, Z., Coufal, R., Kowalow, M.,\&Szcygielski, T.(2011). Peat consolidation - new approach. Archives of Civil Engineering,57(2), 173-186.

3. Kallioglou, P., Tika, T., Koninis, G.,Papadopoulos, S., \&Pitilakis, K. (2009). Shear modulus and damping ratio of organic soils. Geotech Geol Eng, 27(2), 217-235.

4. Waruwu, A., Hardiyatmo, H. C.,\&Rifa'i, A. (2017). Deflection behavior of the nailed slab system-supported embankment on peat soil. Journal of Applied Engineering Science, 15(4), 556 - 563.

5. Waruwu, A., Hardiyatmo, H. C., \&Rifa'i, A. (2016). Compressive behavior of Bagansiapiapi-Riau peat in Indonesia.Electronic Journal of Geotechnical Engineering, 21(16), 5217-5227.

6. Crouse, C. B., Kramer, S. L., Mitchell, R., \& Hushmand, B. (1993). Dynamic tests of pipe pile in saturated peat. J. Geotech. Eng, 119(10), 1550-1567.

7. Moss, R. E. S., \&Hollenback, J. C. (2011). Seismic response of peaty organic soils as a levee foundation material. Geo Frontiers, (pp. 3097-3106).

8. Marto, A., \& Othman, B.A.(2011). The potential use of bamboo as green material for soft clay reinforcement system. International Conference on Environment Science and Engineering, Singapore, (pp. 129133).

9. Kandolkar, S. S., \& Mandal, J. N. (2012). Behaviour of mine waste as reinforced soil. International Journal of Reseach in Engineering and Technology, 1(2), 82-89.

10. Hegde, A., \& Sitharam, T. G. (2015). Use of bamboo in soft-ground engineering and its performance comparison with geosynthetics: experimental studies. Journal of Materials in Civil Engineering, 27(9)1-9.
11. Waruwu, A. (2014). Bamboo reinforcement in shallow foundation on the peat soil. Journal of Civil Engineering Research, 4(3A), 96-102.

12. Waruwu, A., \&Susanti, R. D.(2015). Behavior of soil peat with reinforcement of bamboo grid.IOSR Journal of Engineering, 5(11), 29-36.

13. Waruwu, A. Maulana, \&Halim, H. (2017). Settlement estimation of peat reinforced with bamboo grid under embankment. International Review of Civil Engineering (I.RE.C.E.), 8(6), 299-306.

14. Waruwu, A., Hardiyatmo, H. C., \&Rifa'i, A. (2017). Behavior of nailed-slab system on peat soil under loading. Proceedings of the 1nd Warmadewa University International Conference on Architecture and Civil Engineering, Bali, Indonesia, (pp: 101-107).

15. Susanti, R. D., Maulana, Waruwu, A. (2017). Bearing capacity improvement of peat soil by preloading. ARPN Journal of Engineering and Applied Sciences, 12(1), 121-124.

16. Maulana, Azwar, Susanti, R. D., \&Waruwu, A. (2018). Potential of bamboo pile as reinforcement of peat soil under embankment.ARPN Journal of Engineering and Applied Sciences, 13(1), 52-56.

17. Sinarta, I. N., Rifa'l, A., Fathani, T. F., \& Wilopo, W. (2017). Slope stability assessment using trigger parametersand SINMAP methods on Tamblingan-BuyanAncient Mountain Area in Buleleng Regency, Bali. Geosciences, 7(4), 1-16.

18. Waruwu, A., Halim, H., Nasution, T., \& Hanova, Y., (2018). Bamboo Grid Reinforcement on Peat Soil under Repeated Loading. Journal of Engineeering and Applied Sciences, 13(8): 2190-2196 